\title{
Sexually Mature
}

National Cancer Institute

\section{Source}

National Cancer Institute. Sexually Mature. NCI Thesaurus. Code C158351.

The life stage at which the organism is capable of reproduction. 